\title{
Effects of Lorazepam on Ovary and Ovulation of Balb/C adult Female Mouse
}

\section{ARTICLE INFO}

\section{Article Type}

Original Research

\section{Authors}

Zahra Karami ${ }^{1}$, iD MSc

Parvin Torabzadeh $^{* 2}$ iD $\mathrm{PhD}$

Javad Amini Mahabadi ${ }^{3,4}$ (ID $\mathrm{PhD}$

PhD Student of developmental biology, Department of Biology, Karaj Branch, Islamic Azad University, Karaj, Iran.

Ph.D. Assistant Professor, Department of

Biology, Karaj Branch, Islamic Azad

University, karaj

3 Sarem Fertility and Infertility Research Center (SAFIR), Sarem Women's Hospital, Iran University of Medical Sciences (IUMS), Tehran, Iran.

$\mathrm{PhD}$ of reproductive biology, Gametogenesis Research Center, Kashan University of Medical Sciences, Kashan, Iran.

\section{ABSTRACT}

Aims: The usage of antidepressants and sedatives such as lorazepam can cause side effects, including temporary or permanent infertility. The aim of this study was to evaluate the effect of lorazepam on the ovaries and ovulation of adult female Balb/C mice.

Methods: 75 adult female mice were studied in 5 groups and 15 mice in each group. Lorazepam drug injection was done intraperitoneally (IP) by selecting a fixed dose of $2 \mathrm{mg} / \mathrm{kg}$.bw for three groups at three different times. The study groups were included: the first experimental group for 5 days, the second experimental group for 10 days and the third experimental group for 15 days' injection, sham group (distilled water injection) and control group (without injection). The day after the last injection, the mice were carefully dissected and their ovaries were removed for tissue examination.

Results: Parameters such as animal weight, high and small diameter of ovary, the follicles number of primary, secondary, growing and graph and corpus luteum were significantly decreased by duration increasing of drug injection in experimental groups in compared with control group $(\mathrm{P}<0.05)$. There was a significant increase in parameters such as the number of destructive follicles and folded zona pellucida compared to the control group.

Conclusion: In general, it can be concluded that the use of lorazepam for a long time had a destructive effect on female mice ovaries.

Keywords: Lorazepam; Ovary; Histomorphology; Mice.
*Corresponding Author

Address: Karaj Branch, Islamic

Azad University, karaj, Iran.

Phone: +98 00989123330734

p.torabzadeh@gmail.com

\section{Article History}

Received: April 03, 2020

Accepted: May 17, 2020

e Published: February 02, 2021

Copyright $($ C2021, ASP Ins. This open-access article is published under the terms of the Creative Commons Attribution-Noncommercial 4.0 International License which permits Share (copy and distribute the material in any medium or format) and Adapt (remix, transform, and build 
نتيجه گيرى: به طور كلى مى توان اين كَونه نتيجه كَرفت كه استفاده از داروى لورازيام در مدت زمان طولانى اثر تخريبى بر روى تخمدان موش ائ كانه

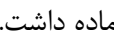

كليد وارْها: لورازيام؛ تخمدان؛ هيستومورفولورى؛ موش.

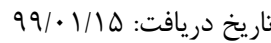

تاريخ يذيرش:

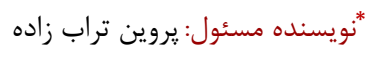

مقدمه

افسردىى و اضطراب با كاهش ميزان بارورى و عوارض دوران باردارى در

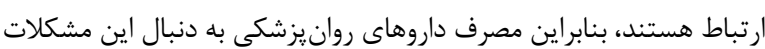

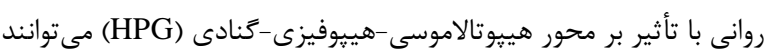

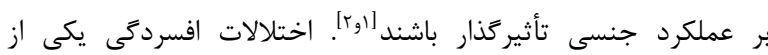

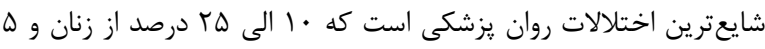

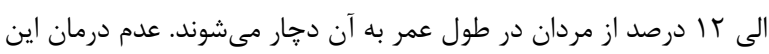

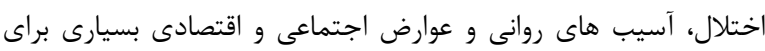

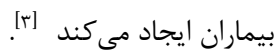

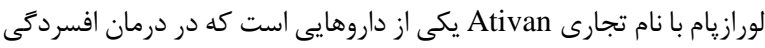

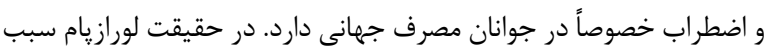

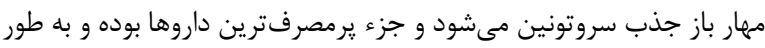

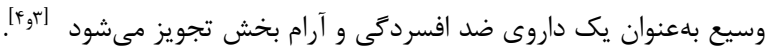

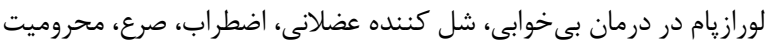

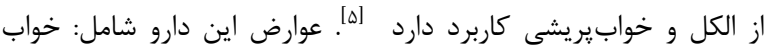

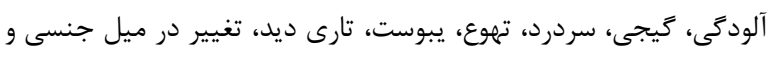

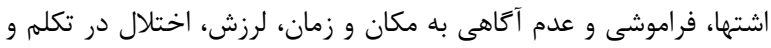

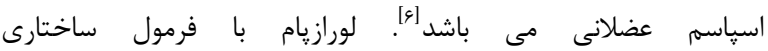
1990 اولين بار در سال بra 191510C12N2O2

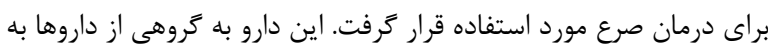

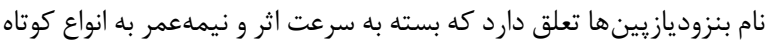

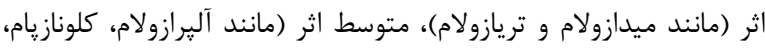

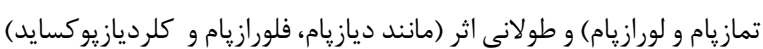

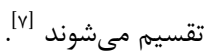

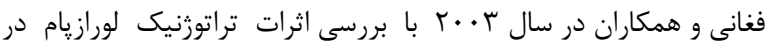

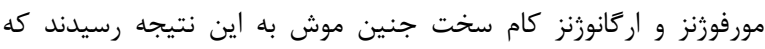

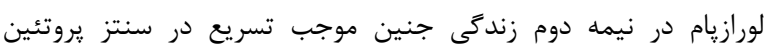

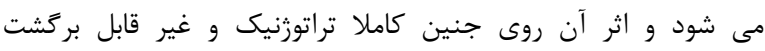

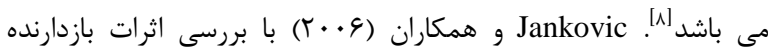

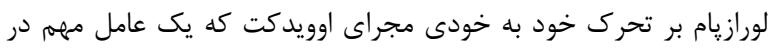

اثر لورازيام بر روى تخمدان و تخمك كذارى موش هاى ماده بالغ نزاد Balb/C

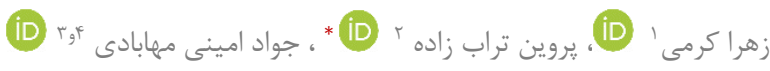
' دانشجوى دكترى زيست شناسى تكوين، مركز زيست شناسى دانشعاه آزاد كرج ،كرج، ايران مركز تحقيقات بارورى و نابارورى صارم، بيمارستان فوق تخصصى صارم،

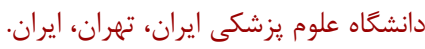

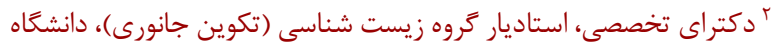
آزاد اسلامى واحد كرج، كرج، ايران.

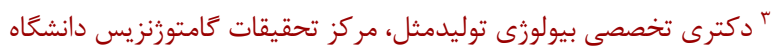
علوم يزشكى كاشان، كاشان، ايران.

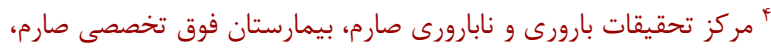
دانشخاه علوم يزشكى ايران، تهران، ايران.

جكيده

اهداف: : استفاده از داروهاى ضد افسردحى و آرامبخش مانند لورازيام مى تواند عوارضى از جمله نابارورى هاى موقت يا دائم ايجاد كند. هدف از

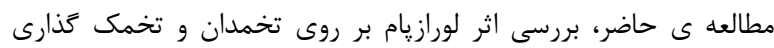
موش هاى ماده بالغ نزاد Balb/C مئ بر باشد.

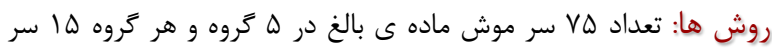

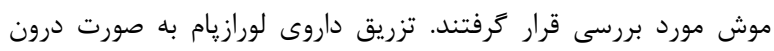

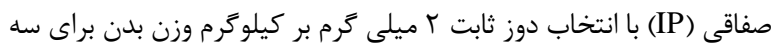

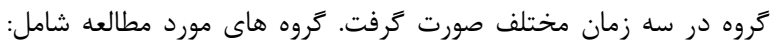

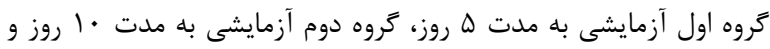

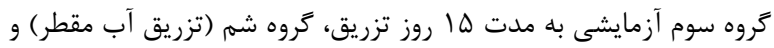

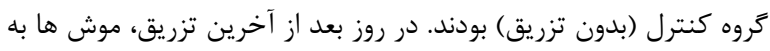

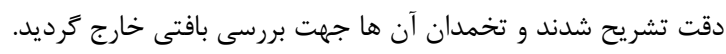

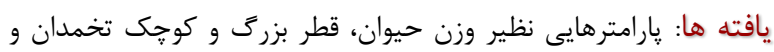

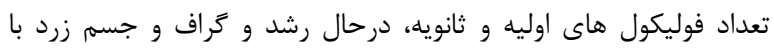

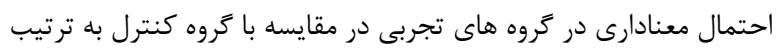

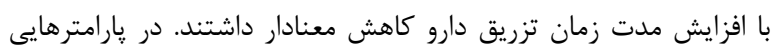

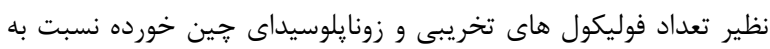

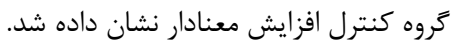


كروه بندى حيوانات

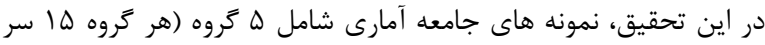

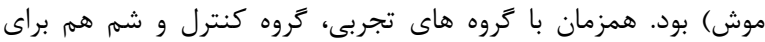

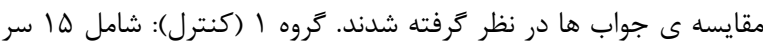

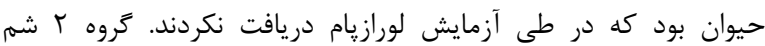

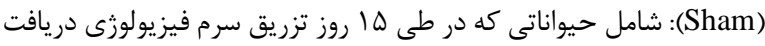

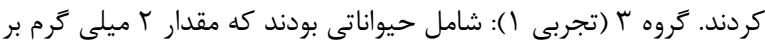

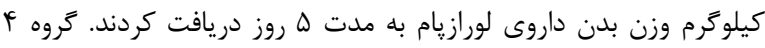

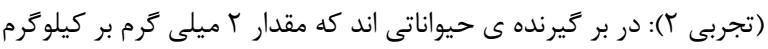

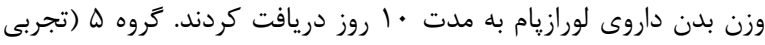

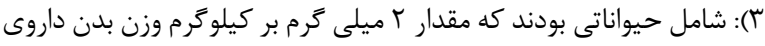

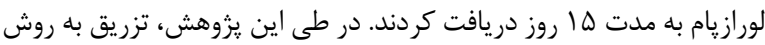
درون صفاقى (Intraperitoneal) صورت كرفت.

بعد از انجام تزريقات، موش ها تشريح و تخمدان آن ها به دقت خارج شد داف دان

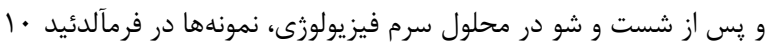

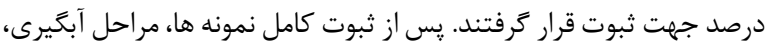

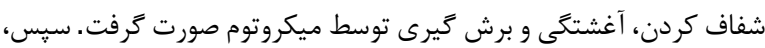

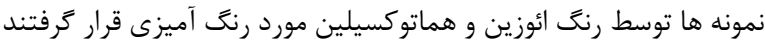

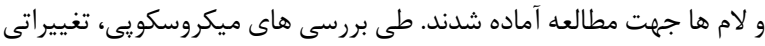

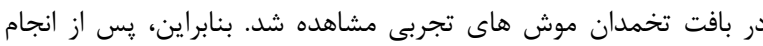

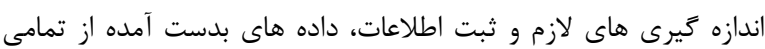

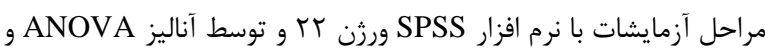

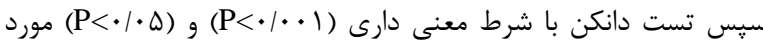

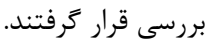

\section{نتايج}

در بررسى بافت تخمدان توسط ميكروسكوٍ نورى در گروه اول تجربى با

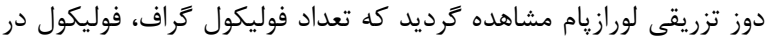

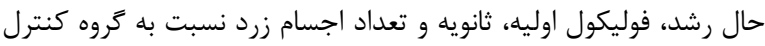
به ميزان قابل توجهى كاهش يافتند و فوليكول هاى در حال تخريب و و زونا

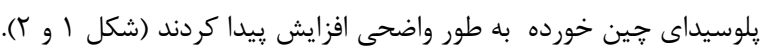

باردارى است با كرفتن بخش هاى لوله فالوٍ ع M بيمار كه تحت درمان با

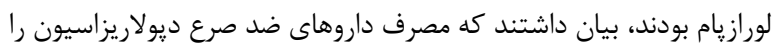

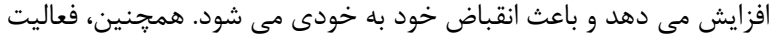

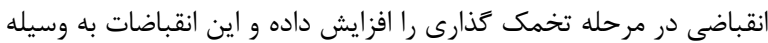

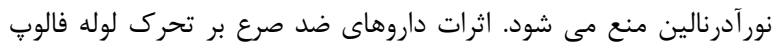

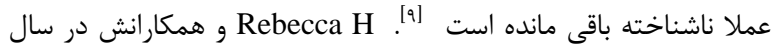

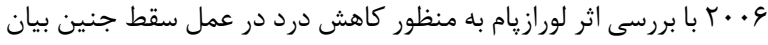

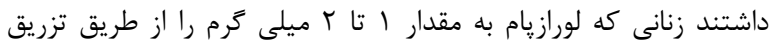

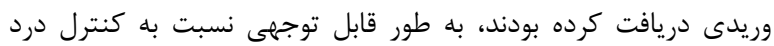

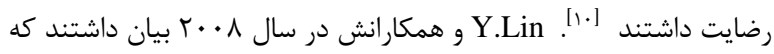

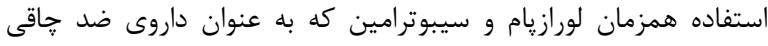

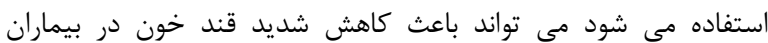

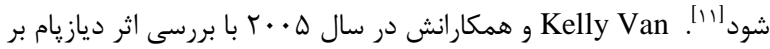
روى رشد فوليكول هاى تخمدان و كيفيت اووسيت به اين نتيجه رسئ رسيدند

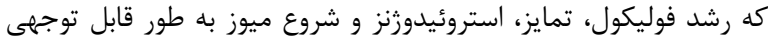
دجار اختلال شد [ri].

با شناخت اثرات مفيد و مضر اين دارو مى توان از مصرف غير اصولى لو لورازيّام

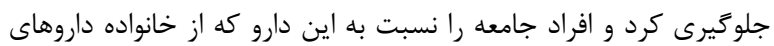

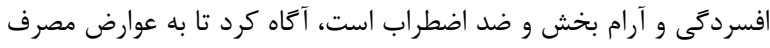

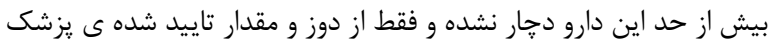

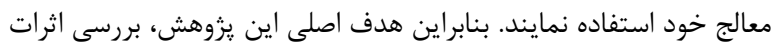

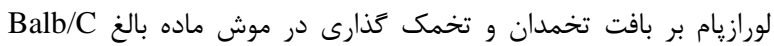
مى باشد.

\section{روش بررسى}

\section{حيوانات و آماده سازى دارو}

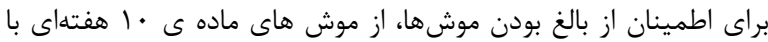

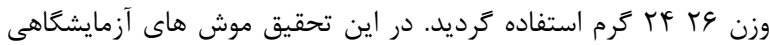

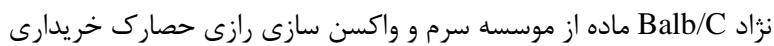

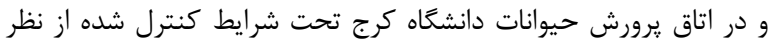

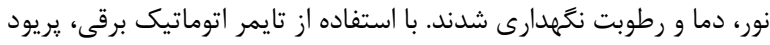

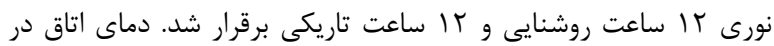

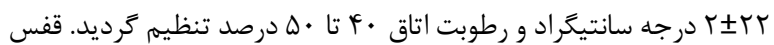

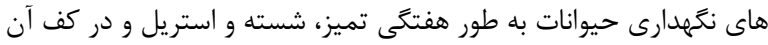

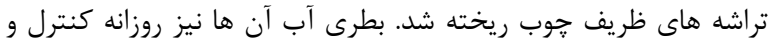

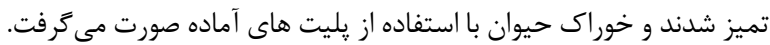

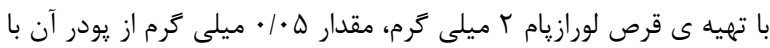

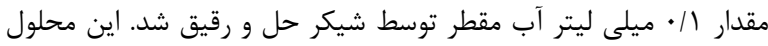

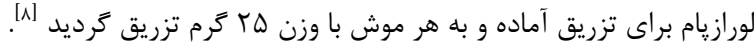



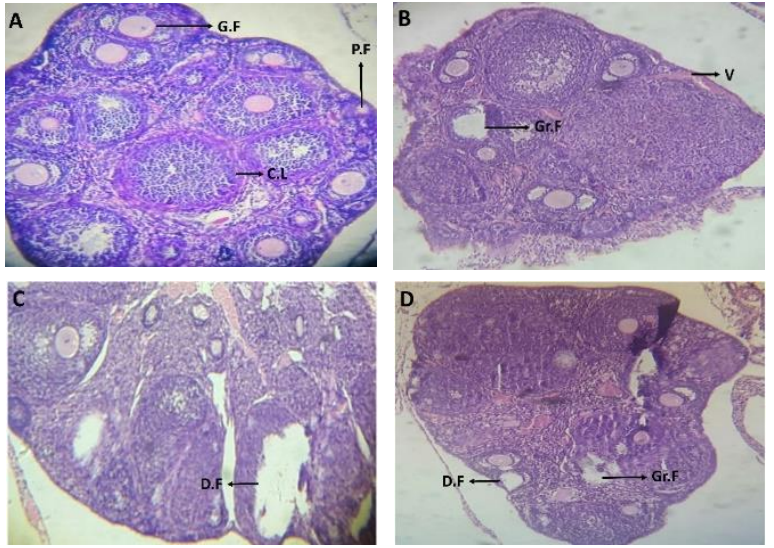

شكل F: ميكروكراف برش عرضى از تخمدان كنترل (A) و تخمدان تجربى با داروى لورازيام

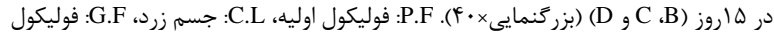

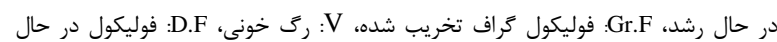
تخريب

در بررسى آمارى و در گروه هاى كنترل، شم و در هر سه گروه تجربى با

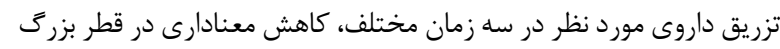

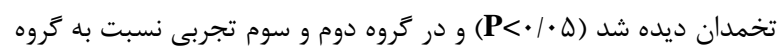

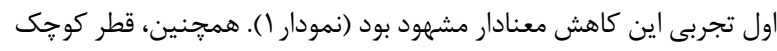

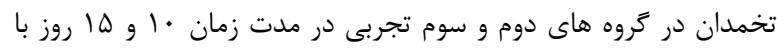

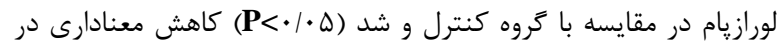

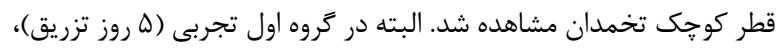

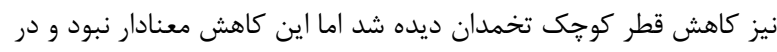

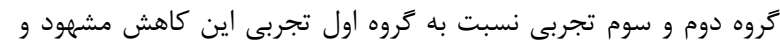

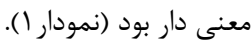

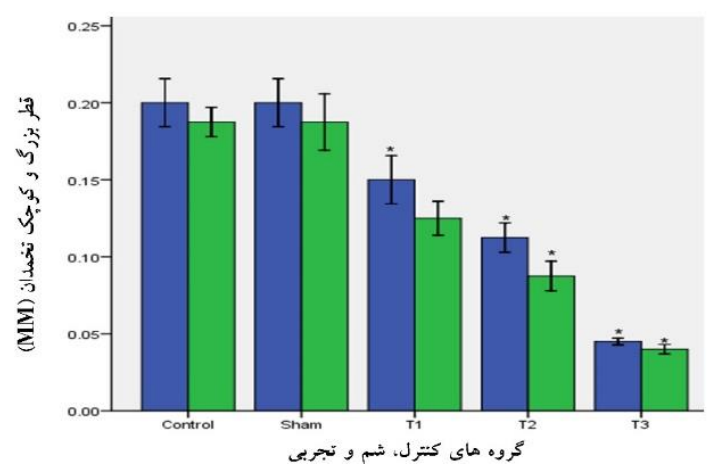

بزرى كوجك

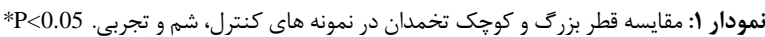

در بررسى تعداد فوليكولهاى اوليه در زروه كنترل و شم از نظر آمارى

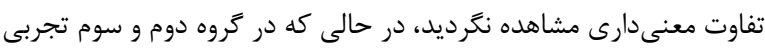
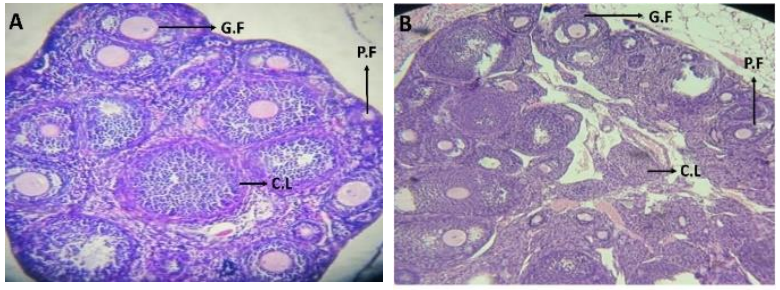

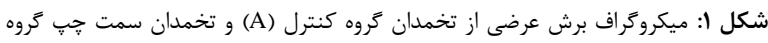

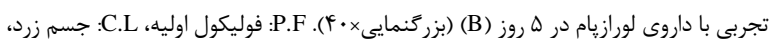

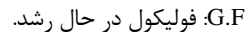
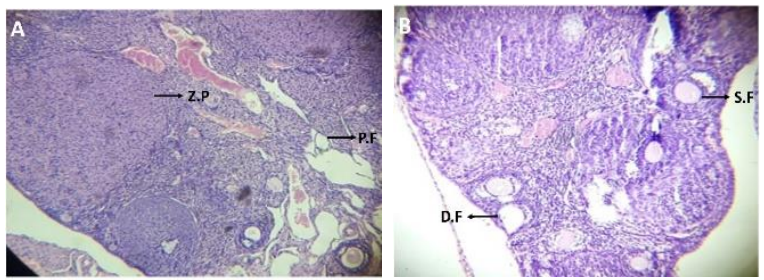

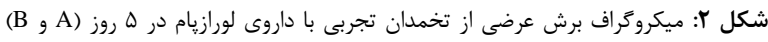

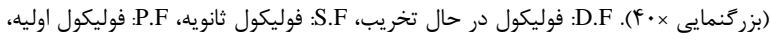

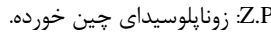

در مطالعات با ميكروسكوٍ نورى در بافت تخمدان در گروه دوم و سوم

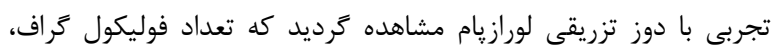

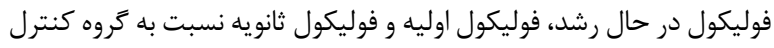

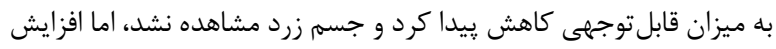

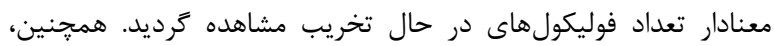
رك هاى خونى قطور تر از گروه كنترل ديده شد (شكل بر ؤ).
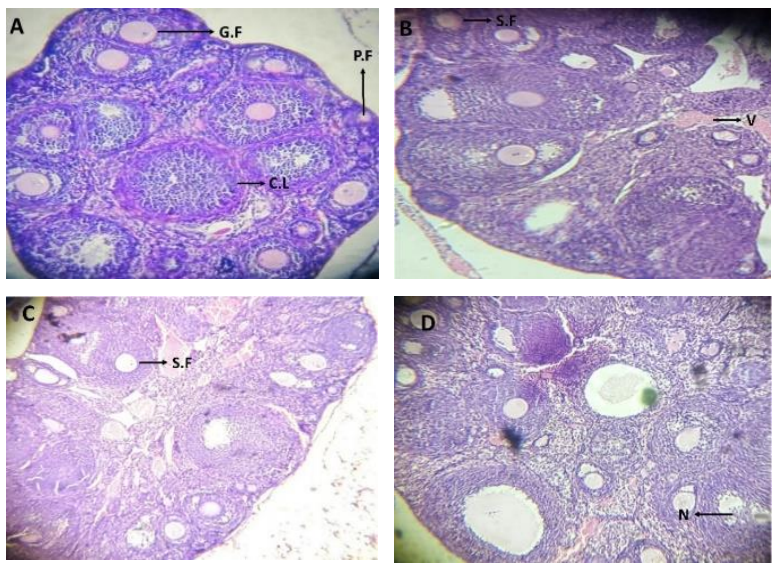

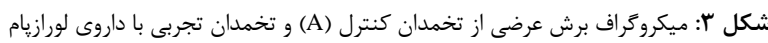

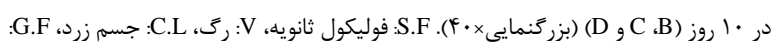

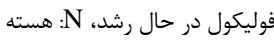




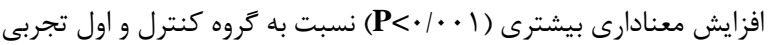

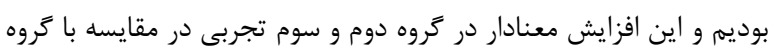

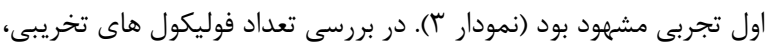

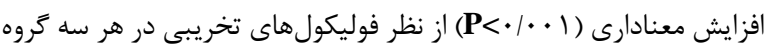

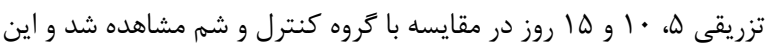

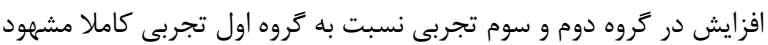
بود (نمودار سا).

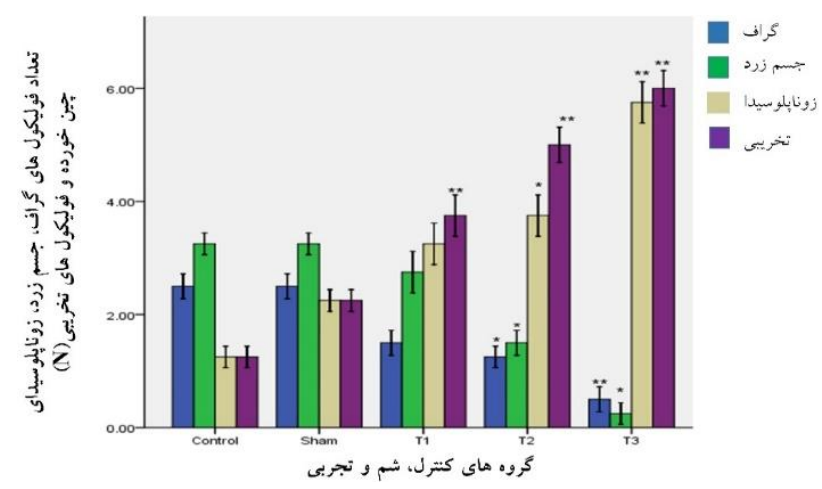

نمودار ץ: مقايسه تعداد فوليكول هاى گراف، جسم زرد، زونايلوسيداى جين خورده و تخريبى

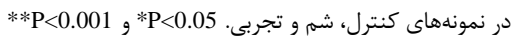

كاهش قطر بزرك و كوحِى و متعاقب آن كاهش اندازه تخمدان از نتايج

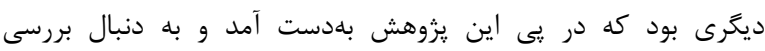

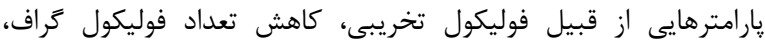

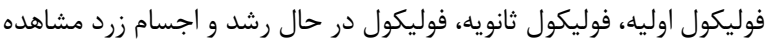

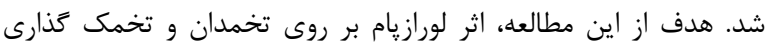

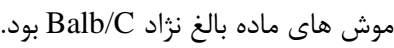

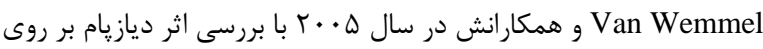

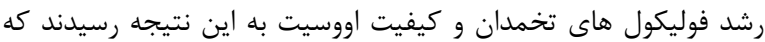

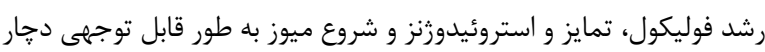

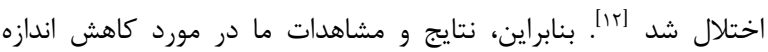

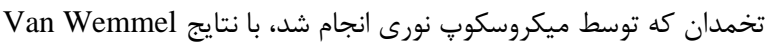

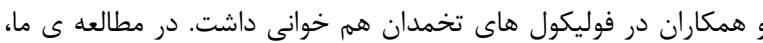

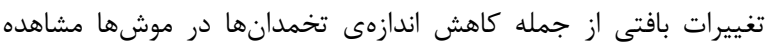

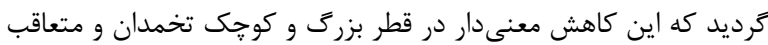

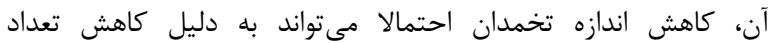

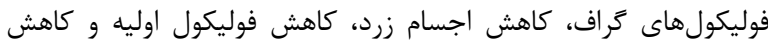

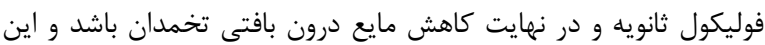

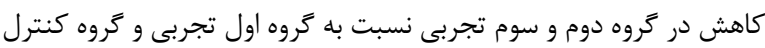

در ها-•إ روز تزريق نسب به كروه كنترل و شم كاهش معنادارى

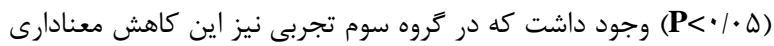

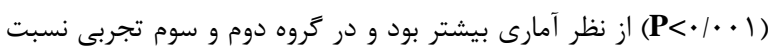

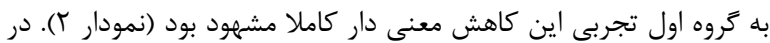

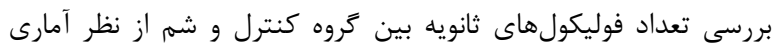

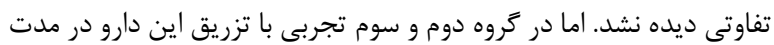

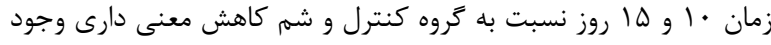

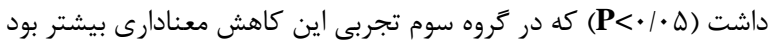

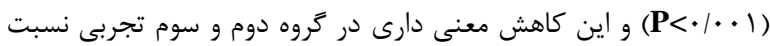

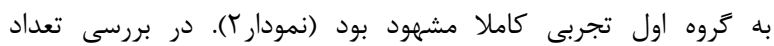

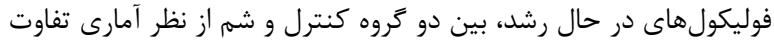

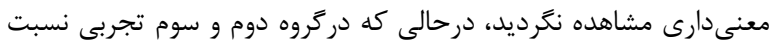

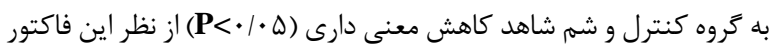

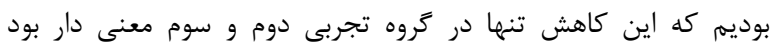

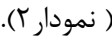

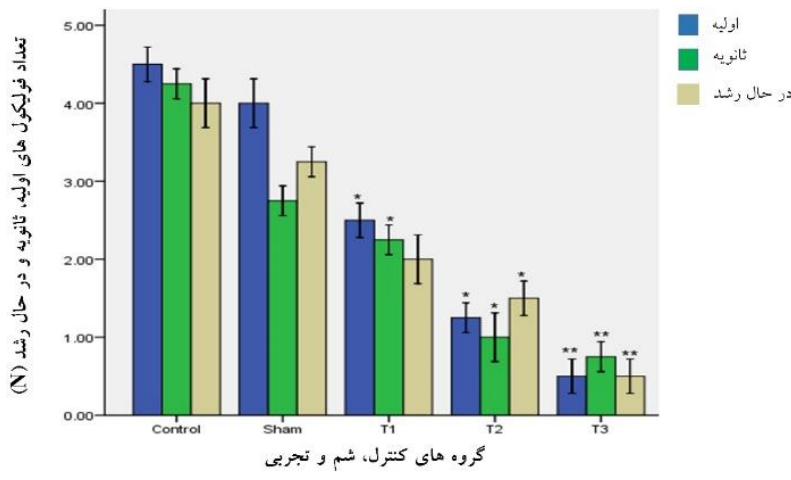

نمودار r م: مقايسه تعداد فوليكولهاى اوليه، ثانويه و در حال رشد تخمدان در نمونههاى **P<0.001 كنترل، شم و تجربى. ن

از نظر بررسى تعداد فوليكولهاى تَراف، در كروه كنترل و شم از نظر آمارى دئ

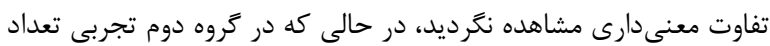

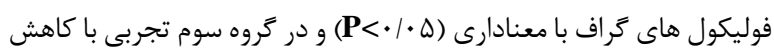

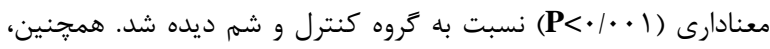

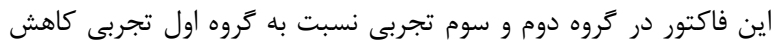

معنادار بود (نمودار سٓ). در بررسى بارامتر تعداد اجسام زرد، بين كَروه كنترل و شمه از نظر آمارى

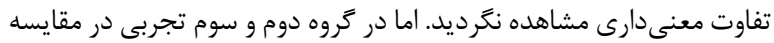

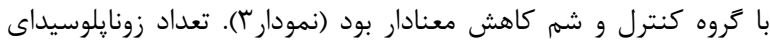

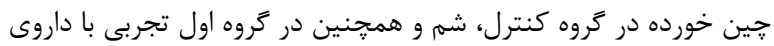

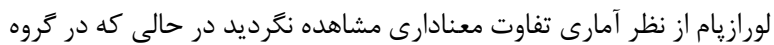

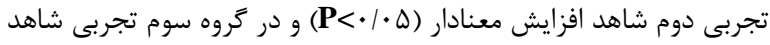


جين خورده هم نسبت به گروه كنترل و هم در بين گروههاى تجربى به ترتيب افزايش زمان تزريق مشاهده ترديد.

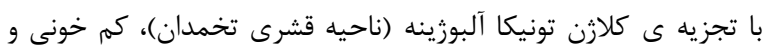

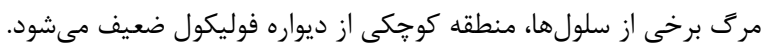

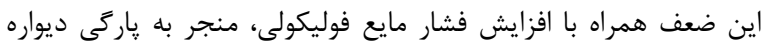

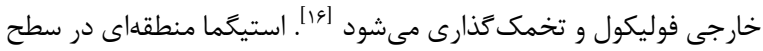

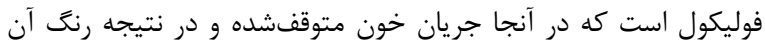

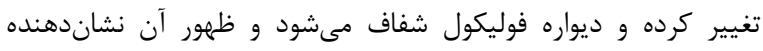

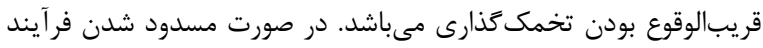

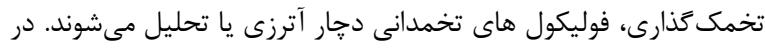

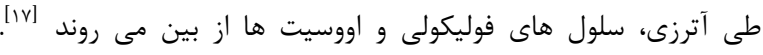

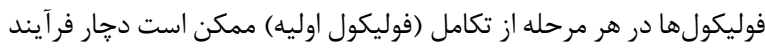

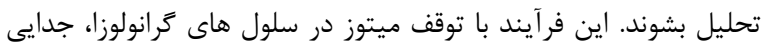

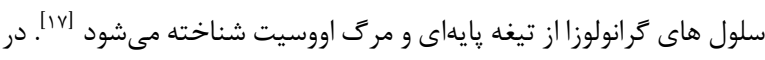
يروهش حاضر در گروه دوم و سوم تجربى، فوليكول هاى تخريبى و زونا

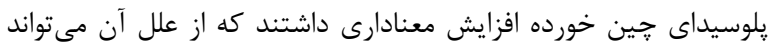

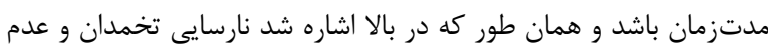

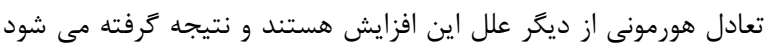

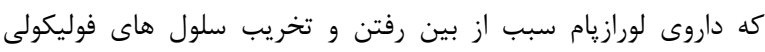

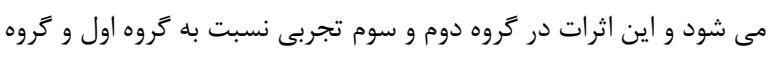

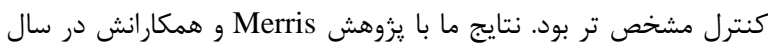

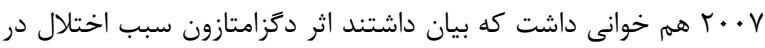

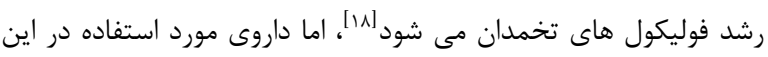
مطالعه با داروى تحقيق ما متفاوت بود. ماي تخدي

\section{نتيجه كيرى}

با توجه به اين مشاهدات مى توان اين طور نتيجه كرفت كه استفاده از

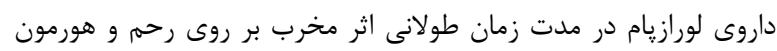

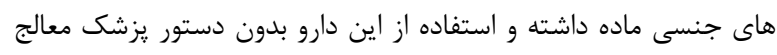

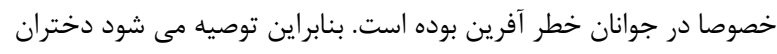

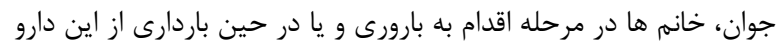

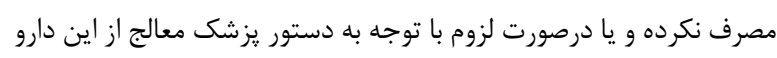

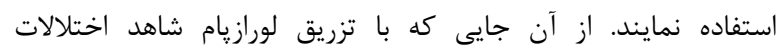

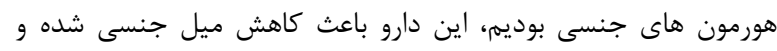

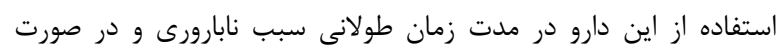

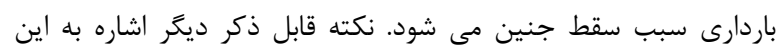

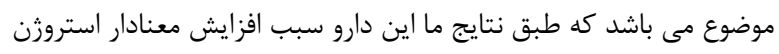

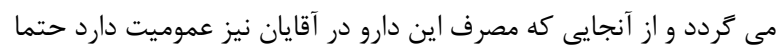

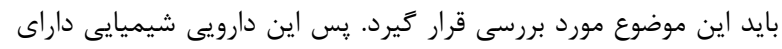
ارزش سرمايه كذارى از جنبه ايجاد نابارورى موقتى رورد رادي دارد.
بيشتر بود. به طورى كه اثر اين دارو در مدت زمان طولانى بر روى بافت تخمدان مخرب بود. در اين يزوهش، تعداد فوليكول اوليه، ثانويه و در حال رشد كاهش يافت.

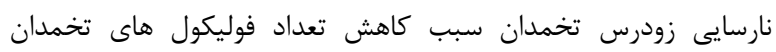

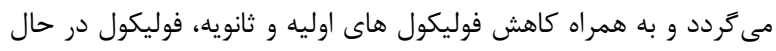

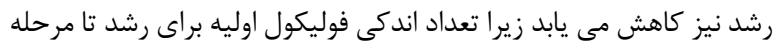

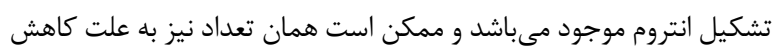

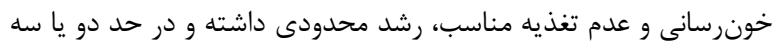

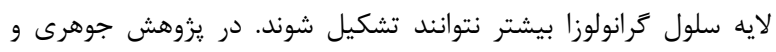

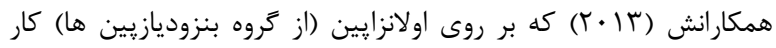

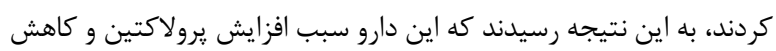

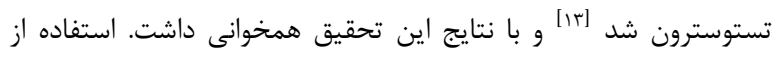

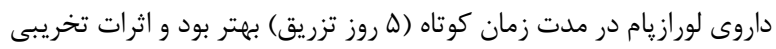

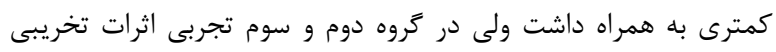

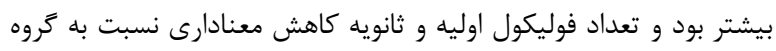

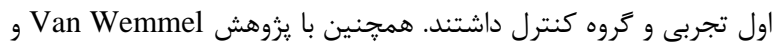

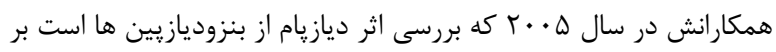

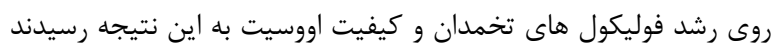

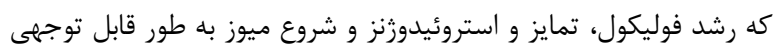

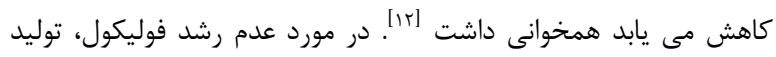

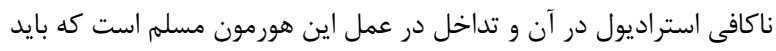

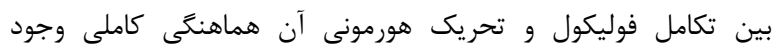

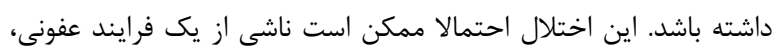

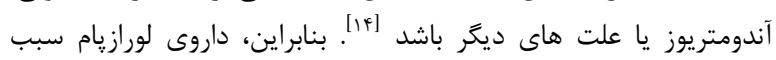

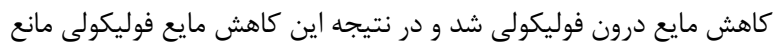

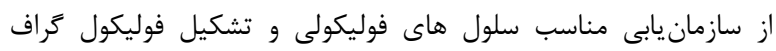

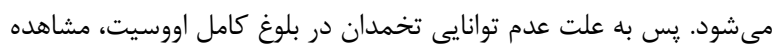

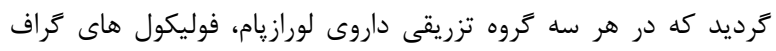

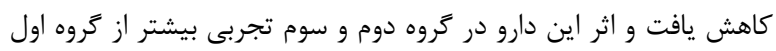

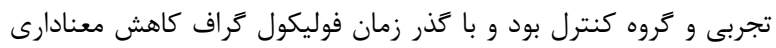
داشت (نمودار س). آزاد شدن تخمك سبب تبديل سلول هاى ترانولوزا و سلول هاى تكاى

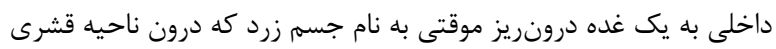

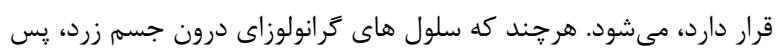

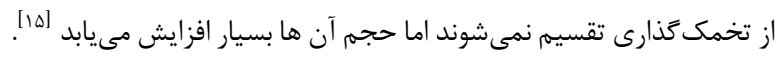

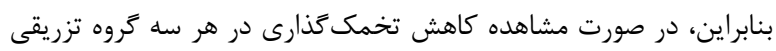

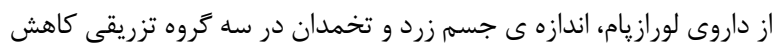

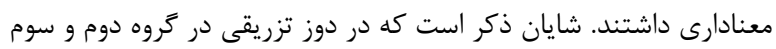

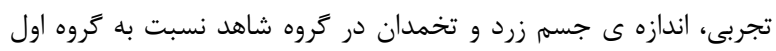

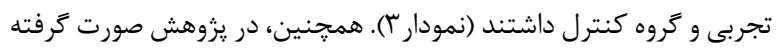

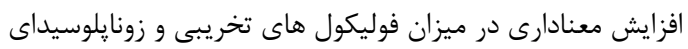


$.4 \quad$ Nguyen N, Fakra E, Pradel V, Jouve E, Alquier C, Le Guern ME, et al. Efficacy of etifoxine compared to lorazepam monotherapy in the treatment of patients with adjustment disorders with anxiety: a double-blind controlled study in general practice. Human Psychopharmacology: Clinical and Experimental. 2006;21(3):139-49.

.5 Wiebe E, Podhradsky L, Dijak V. The effect of lorazepam on pain and anxiety in abortion. Contraception. 2003;67(3):219-21.

.6 Ahir BK, Pratten MK. Association of anxiolytic drugs diazepam and lorazepam, and the antiepileptic valproate, with heart defectsEffects on cardiomyocytes in micromass (MM) and embryonic stem cell culture. Reproductive toxicology. 2011;31(1):66-74.

.7 Jurand A, Martin L. Cleft palate and open eyelids inducing activity of lorazepam and the effect of flumazenil, the benzodiazepine antagonist. Pharmacology \& toxicology. 1994;74(6):228-3.5

.8 Faghani M, nadia sZ, salsabili N. Effect of lorazpam on the anatomical development of morphogenesis of the secondary palate in the rat embryo. Journal of Ilam University of Medical Sciences. 2003;10(36-37):21-6.

.9 Kanto J, Aaltonen L, Liukko P, Mäenpää

K. Transfer of lorazepam and its conjugate across the human placenta. Acta pharmacologica et toxicologica. 1980;47(2):130-4.

.10 Allen RH, Kumar D, Fitzmaurice G, Lifford KL, Goldberg AB. Pain management of first-trimester surgical abortion: effects of selection of local anesthesia with and without lorazepam or intravenous sedation. Contraception. 2006;74(5):407-13.

.11 Lin Y-Y, Hsu C-W, Chu S-J, Tsai S-H. Another dangerous combination for hypoglycemic coma: concurrent use of sibutramine and lorazepam. QJM: An International Journal of Medicine. 2008;101(3):243-5.

.12 Van Wemmel K, Gobbers E, Eichenlaub-Ritter U, Smitz J, Cortvrindt R. Ovarian follicle bioassay reveals adverse effects of diazepam exposure upon follicle development and oocyte quality .Reproductive Toxicology. 2005;20(2):183-93.

.13 Johari H, Khatamsaz S, Dehghani K, Hemayatkhah Jahromi V, Jamali H, Kafilzadeh F,

\author{
تشكر و قدردانى: \\ اين مقاله ى استخراجى از پايان نامه وى دورهى

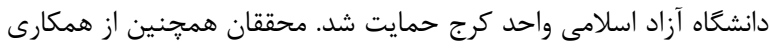 \\ دلسوزانه همه يرسنل در اين دانشعاه قدردانى مى كى كنئد.
}

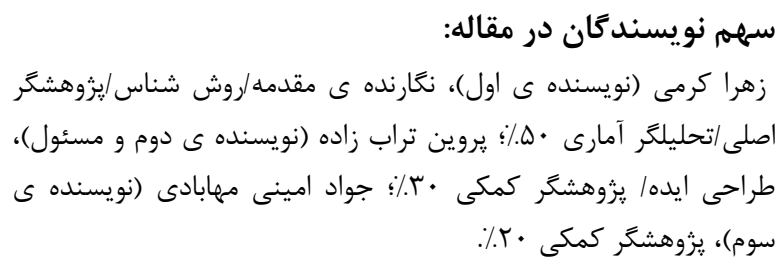

منابع: (2) n

.1 Ebrahimian A, Hemayatkhah-Jahromi V, Forouzanfar M. Effect of fluoxetine on hormonal axis of pituitary-gonad in adult female rats. Feyz Journal of Kashan University of Medical Sciences. 2014;17(6):517-21.

.2 Fu W, Wilhelm LO, Wei Y, Zhou G, Schwarzer R .Emotional intelligence and dyadic satisfaction buffer the negative effect of stress on prenatal anxiety and depressive symptoms in Chinese women who are pregnant with twins. Anxiety, Stress, \& Coping. 2020:1-13.

.3 Lakatos E, Szigeti JF, Ujma PP, Sexty R, Balog P. Anxiety and depression among infertile women: a cross-sectional survey from Hungary. BMC women's health. 2017;17(1):48. 
et al. Effect of Olanzapine on Pituitary-Gonad Axis and Spermatogenesis in Adult Male Rats. Journal of Fasa University of Medical Sciences. 2013;3(1):42-8.

.14 Bauer J, Stoffel-Wagner B, Flügel D, Kluge M, Elger C. The impact of epilepsy surgery on sex hormones and the menstrual cycle in female patients. Seizure. 2000;9(6):389-93.

.15 Devoto L, Kohen P, Munoz A, Strauss III JF .Human corpus luteum physiology and the luteal-phase dysfunction associated with ovarian stimulation. Reproductive biomedicine online. 2009;18:19-24.

.16 Maslyanskaya S, Talib HJ, Northridge JL, Jacobs AM, Coble C, Coupey SM. Polycystic ovary syndrome: an under-recognized cause of abnormal uterine bleeding in adolescents admitted to a children's hospital. Journal of pediatric and adolescent gynecology. 2017;30(3):349-55.

.17 Luciano AM, Sirard M-A. Successful in vitro maturation of oocytes: a matter of follicular differentiation. Biology of reproduction. 2018;98(2):162-9.

.18 Van Merris V, Van Wemmel K, Cortvrindt R. In vitro effects of dexamethasone on mouse ovarian function and preimplantation embryo development. Reproductive Toxicology. 2007;23(1):32.41- 